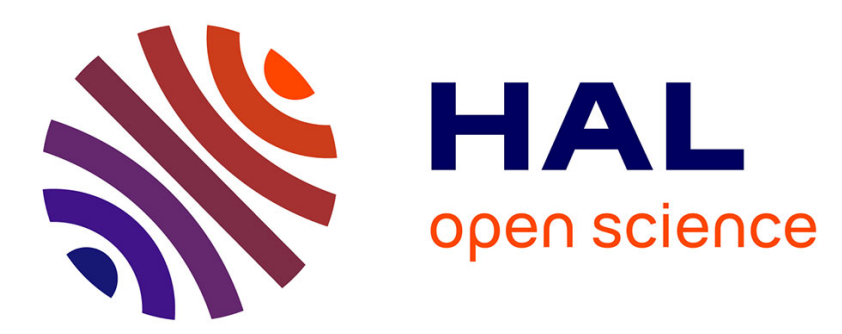

\title{
A new way to include the grain shape in texture simulations with the Taylor model
}

H.J. Bunge, F. Wagner, P. van Houtte

\section{To cite this version:}

H.J. Bunge, F. Wagner, P. van Houtte. A new way to include the grain shape in texture simulations with the Taylor model. Journal de Physique Lettres, 1985, 46 (23), pp.1109-1113. 10.1051/jphyslet:0198500460230110900 . jpa-00232944

\section{HAL Id: jpa-00232944 https://hal.science/jpa-00232944}

Submitted on 1 Jan 1985

HAL is a multi-disciplinary open access archive for the deposit and dissemination of scientific research documents, whether they are published or not. The documents may come from teaching and research institutions in France or abroad, or from public or private research centers.
L'archive ouverte pluridisciplinaire HAL, est destinée au dépôt et à la diffusion de documents scientifiques de niveau recherche, publiés ou non, émanant des établissements d'enseignement et de recherche français ou étrangers, des laboratoires publics ou privés. 
Classification

Physics Abstracts

$62.20-62.20 \mathrm{~F}-81.40 \mathrm{E}$

\title{
A new way to include the grain shape in texture simulations with the Taylor model
}

\author{
H. J. Bunge $\left({ }^{1}\right)$, F. Wagner $\left({ }^{2}\right)$, P. I. Welch $\left({ }^{1}\right)$ and P. Van Houtte $\left({ }^{3}\right)$ \\ (1) Institut für Metallkunde und Metallphysik, 3392 Clausthal-Zellerfeld, F.R.G. \\ $\left({ }^{2}\right)$ Laboratoire de Métallurgie Structurale, Université de Metz, 57045 Metz Cedex, France \\ $\left({ }^{3}\right)$ Dept. Metaalkunde, Katholieke Universiteit Leuven, Belgium
}

(Reçu le 15 juillet 1985, accepté le 9 octobre 1985)

\begin{abstract}
Résumé. - L'utilisation de la relation de Hall-Petch dans les simulations de texture à l'aide du modèle de Taylor-Bishop-Hill est proposée comme moyen de prise en compte de la forme des grains. Les résultats obtenus sont confrontés à ceux du modèle de Taylor classique ou relaxé dans le cas d'une texture simple et les conséquences pour le coefficient d'anisotropie sont examinées.
\end{abstract}

\begin{abstract}
The use of the Hall-Petch relation in texture simulations with the Taylor-Bishop-Hill model is proposed as a mean to take into account grain shape effect. The results are compared with those obtained with the usual and relaxed constraint Taylor model for a simple texture and the consequences for the anisotropy coefficient are investigated.
\end{abstract}

\section{Introduction.}

The most used model in polycrystal deformation studies is the Taylor-Bishop-Hill one; it has allowed to predict crystallographic textures which are in qualitative agreement with the experimental ones for cold worked materials $[1,2]$. In order to improve these predictions the so called relaxed constraint Taylor-Bishop-Hill model was developed $[3,4]$; because of assumptions on the grain shape (pancake or lath for example) the strains on the small surfaces of a grain are no more imposed which, as a consequence, allows to restrict the number of the required active slip systems ( 3 or 4 instead of 5 in the usual model). This relaxed constraint model has produced very realistic textures for f.c.c. rolled metals but large discrepancies with experimental textures are observed in the case of b.c.c. metals [5].

The Taylor-Bishop-Hill model on one side, and the knowledge of the crystallographic texture of a material on the other side, allow also the calculation of the anisotropy coefficient $r$ (also called Lankford parameter). It was observed for low carbon steels that the predictions for $r$ are in good agreement with the experimental values for large grain sizes, whereas a systematic deviation occurs in the case of small grain sizes [6].

We propose hereafter a new way to take into account the grain shape effect in the frame of the Taylor-Bishop-Hill theory. 


\section{Use of the Hall-Petch relation in texture simulations.}

In a simulation the total strain is achieved with a series of steps, each one corresponding to a small deformation applied to a finite number of " grains ». At each step the c.r.s.s. (critical resolved shear stresses) of the potential slip systems can be defined. Because of the lack of a well established law for the work-hardening they are usually held as constants during the whole simulation. As a matter of fact the Hall-Petch relation indicates that the c.r.s.s. is dependent on the mean grain size $\bar{l}$ :

$$
\sigma_{\mathrm{c}}=\sigma_{0}+k \bar{l}^{-1 / 2}
$$

where $\sigma_{0}$ is the c.r.s.s. for an " infinitely large " grain and $k$ is a constant. If the grain is sphere shaped the size $l$ is the same in every direction and the use of the relation (1) in the simulation scheme has no influence on the final texture since the hardening is isotropic. If, on the contrary, the grain shape changes during the deformation (as in the case of rolling for example) the size of a grain is then very different according to the considered direction. It is thus possible at each step of deformation and for each grain to define the c.r.s.s. with (1) by taking into account the shape and the orientation of the grain.

\section{Formalism.}

We assumed that a grain can be described as an ellipsoïd with the parameters $a, b$ and $c$ and that its principal axes coïncide with the specimen coordinate system (usually rolling, transverse and normal directions for rolled materials). The parameters $a, b, c$ can either be fixed once at the beginning of the calculation or changed in correlation with the deformation. The orientation $g^{j}$ of the $j$ th grain ( $g^{j}$ is a rotation matrix) defines its orientation and is known at each step of the calculation. The slip direction associated to the $i$ th slip system which is $\mathrm{d}_{i}^{\mathrm{g}}$ in the grain coordinate system becomes in the specimen coordinate system $\mathbf{d}_{i}^{\mathbf{s}}$ :

$$
\mathbf{d}_{i}^{\mathbf{s}}=g^{j} \mathbf{d}_{i}^{\mathbf{g}} .
$$

It is thus possible to determine the length $l_{i}^{j}$ which is intersected by the ellipsoid along the direction $d_{i}^{\text {s }}$ by means of easy geometrical considerations :

$$
l_{i}^{j}=2 /\left(d_{i 1}^{\mathrm{s}} / a^{2}+d_{i 2}^{\mathrm{s}} / b^{2}+d_{i 3}^{\mathrm{s}} / c^{2}\right)^{1 / 2}
$$

where the indices $1,2,3$ denote the components of $d_{i}^{\mathrm{s}}$.

The c.r.s.s. $\sigma_{c i}^{j}$ which is associated to the $i$ th slip system of the $j$ th grain is then calculated by using the Hall-Petch relation (1) with $\bar{l}=l_{i}^{j}$. It is also possible to determine the value of $l_{i}^{j}$ from the area of the slip plane which is intercepted by the ellipsoïd.

\section{Results.}

In order to test the feasibility of such a simulation we have chosen a crystallographic texture which consists in 6 ideal orientations with different weights (these are the orientations which usually appear in cold-rolled steels); the list is given in table I.

The simulated deformations were elongations; $\alpha$ is the angle between the elongation axis and the rolling direction. The deformation tensor in such a test reads in its principal axes :

$$
\Delta \eta\left(\begin{array}{rrc}
1 & 0 & 0 \\
0 & -q & 0 \\
0 & 0 & -(1-q)
\end{array}\right)
$$

where $q$ is the contraction ratio and $\Delta \eta$ the absolute value of the deformation which is assumed to be small. For each $\alpha$ value the calculation is repeated for 13 values of $q$ (between 0 and 1 ). 
Table I. - The 6 ideal orientations and their weights as used in the simulations.

\begin{tabular}{|c|c|c|c|c|}
\hline Orientation & \multicolumn{3}{|c|}{ Corresponding Euler angles } & Weight \\
\hline $\begin{array}{l}\{001\}<110\rangle \\
\{112\}\langle 110\rangle \\
\{111\}\langle 110\rangle \\
\{111\}\langle 112\rangle \\
\{110\}\langle 110\rangle \\
\{110\}\langle 001\rangle\end{array}$ & $\begin{array}{r}0^{\circ} \\
0^{\circ} \\
0^{\circ} \\
90^{\circ} \\
0^{\circ} \\
90^{\circ}\end{array}$ & $\begin{array}{l}0^{\circ} \\
35.3^{\circ} \\
54.7^{\circ} \\
54.7^{\circ} \\
90^{\circ} \\
90^{\circ}\end{array}$ & $\begin{array}{l}45^{\circ} \\
45^{\circ} \\
45^{\circ} \\
45^{\circ} \\
45^{\circ} \\
45^{\circ}\end{array}$ & $\begin{array}{l}0.025 \\
0.15 \\
0.40 \\
0.375 \\
0.025 \\
0.025\end{array}$ \\
\hline
\end{tabular}

It is indeed considered that the simulation for which the mean Taylor factor $\bar{M}(q)$ (which is proportional to the internal work) is minimal corresponds to the real tensile test and that the corresponding value of $q$, denoted $q_{\min }$, corresponds to the real contraction ratio of the test [7]; this is illustrated in figure 1 for $\alpha=0^{\circ}$. This $q_{\min }$ value is related to the anisotropy coefficient $r$ :

$$
r=q_{\min } /\left(1-q_{\min }\right) \text {. }
$$

Figure 2 shows the values of $\bar{M}\left(q_{\min }\right)$ as a function of $\alpha$ for several simulations. In each case the used slip systems are $\{110\}\langle 111\rangle$ and $\{112\}\langle 111\rangle$. For the simulations with the usual or relaxed constraint Taylor model all the c.r.s.s. have the same value. For the simulations including the Hall-Petch relation the following credible conditions are used $: a / b=b / c=4 ; a=8 \mu \mathrm{m}$ for the ellipsoïd and $\sigma_{0}=4.0 \mathrm{kgf} / \mathrm{mm}^{2} ; k=3.0 \mathrm{kgf} / \mathrm{mm}^{3 / 2}$ in the Hall-Petch relation according to data of the literature for low carbon steels [8].

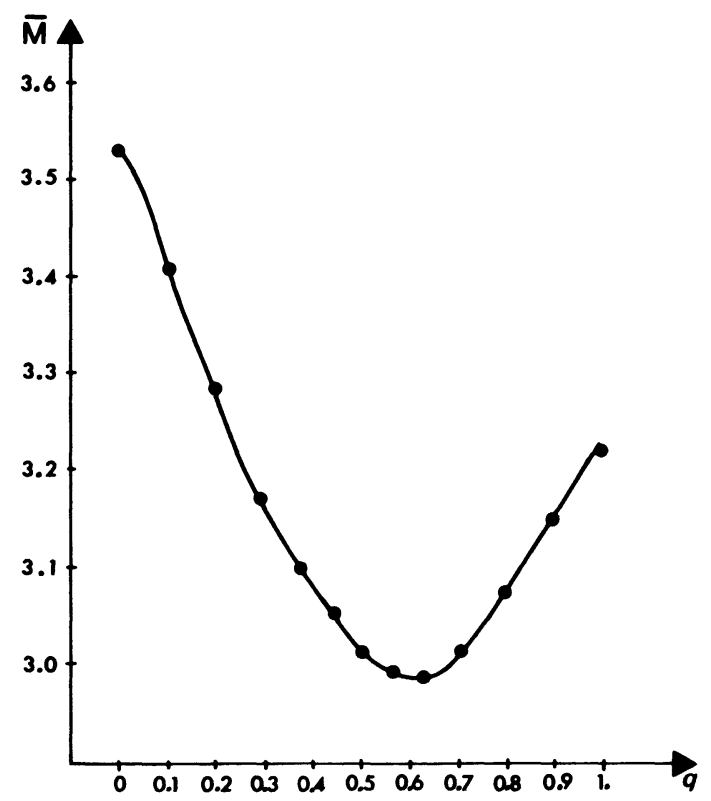

Fig. 1. - Variation of the mean Taylor factor with $q$ (usual model $; \alpha=0^{\circ}$ ). 


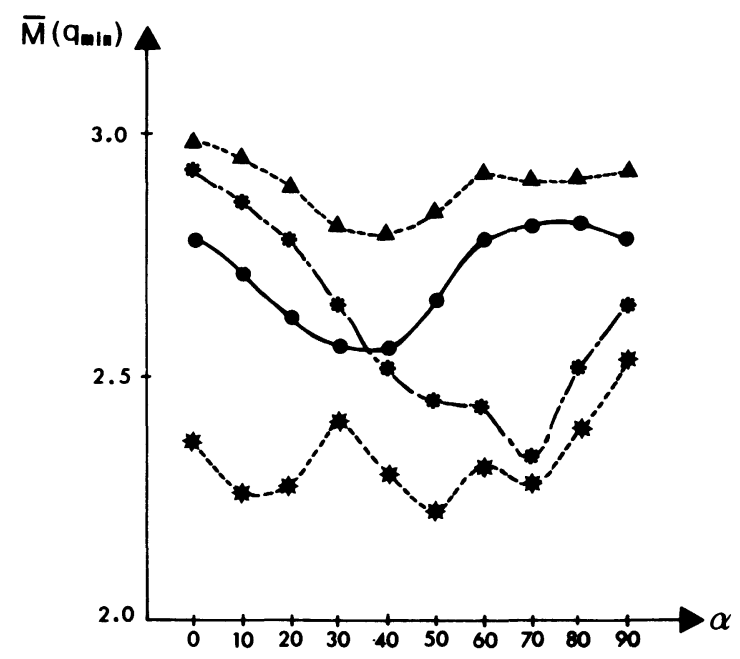

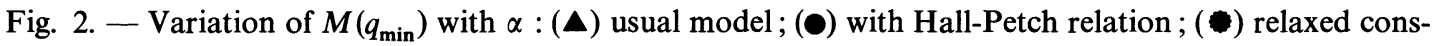
traint lath; (*) relaxed constraint pancake.

It appears clearly that the use of the Hall-Petch relation in the simulations modifies significantly the Taylor factor $\bar{M}\left(q_{\min }\right)$ especially the amplitude of its variations with $\alpha$. As a consequence the evolution of the contraction ratio $q_{\min }$ (and then of the anisotropy coefficient $r$ ) with $\alpha$ is also modified which is shown in figure 3.

a)

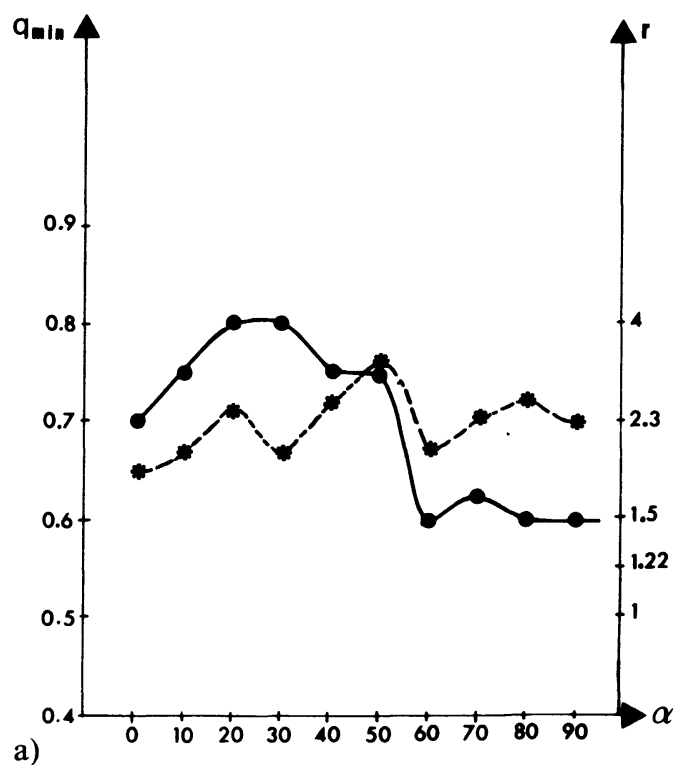

b)

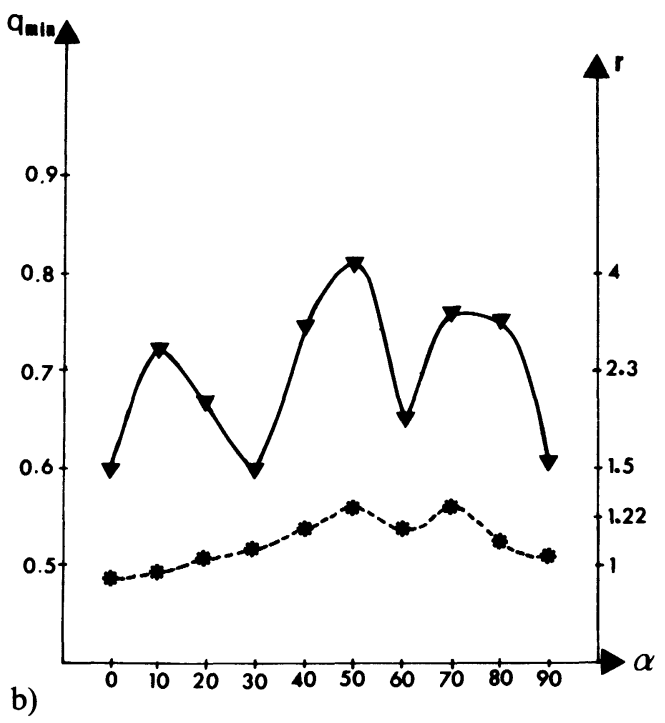

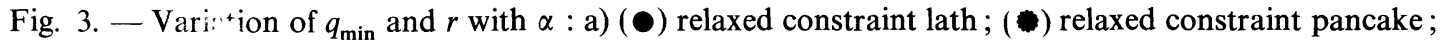
b) $(\boldsymbol{\nabla})$ usual model; $(\bullet)$ with Hall-Petch relation. 


\section{Conclusion.}

Our purpose was to propose a new way to take into account the grain shape effect in the frame of the Taylor-Bishop-Hill model and to demonstrate for a simplified texture how it changes the final result in comparison with the usual or relaxed constraint models. These new simulations have now to be extended to more complex textures and for several values of the Hall-Petch law parameters in order to make comparisons with experimental results (measured anisotropy coefficients for example). The knowledge of the modifications observed for the main orientations of the texture of cold rolled steels seems to us an efficient help for this next step.

\section{References}

[1] Bunge, H. J., Kristall. Techn. 5 (1970) 145.

[2] Gil Sevillano, J., Van Houtte, P., Aernoudt, E., "Large Strain work hardening and textures ", Progress in Materials Science 25 (1980) 69.

[3] HonefF, H., Mecking, H., Proceedings ICOTOM 5, Vol. 1 (Springer Verlag) 1978, p. 265.

[4] Van Houtte, P., Proceedings ICOTOM 6, Vol. 1 (The Iron and Steel Institute of Japan) 1981, p. 428.

[5] Van Houtte, P., Proceedings ICOTOM 7 (Netherland Society for Material Sciences) 1984, p. 7.

[6] Welch, P. I., Bunge, H. J., Metal. Sci. J., in print.

[7] Bunge, H. J., Schulze, M., Grzesix, D., Peine Salzgitter Ber. (1980) 1.

[8] DaHL, W., ReEs, H., " Grundlagen des Festigkeits- und Bruchverhaltens » (Sthahleisen Verlag) 1974, p. 53. 